


\title{
A Carta Constitucional portuguesa de 1826 na Europa: um exame a partir de documentos espanhóis
}

Autor(es): $\quad$ Brancato, Braz Augusto Aquino

Publicado por: Imprensa da Universidade de Coimbra

URL persistente:

URl:http://hdl.handle.net/10316.2/43785

DOI:

DOI:https://doi.org/10.14195/2183-8925_10_26

Accessed : $\quad$ 26-Apr-2023 07:52:20

A navegação consulta e descarregamento dos títulos inseridos nas Bibliotecas Digitais UC Digitalis, UC Pombalina e UC Impactum, pressupõem a aceitação plena e sem reservas dos Termos e Condições de Uso destas Bibliotecas Digitais, disponíveis em https://digitalis.uc.pt/pt-pt/termos.

Conforme exposto nos referidos Termos e Condições de Uso, o descarregamento de títulos de acesso restrito requer uma licença válida de autorização devendo o utilizador aceder ao(s) documento(s) a partir de um endereço de IP da instituição detentora da supramencionada licença.

Ao utilizador é apenas permitido o descarregamento para uso pessoal, pelo que o emprego do(s) título(s) descarregado(s) para outro fim, designadamente comercial, carece de autorização do respetivo autor ou editor da obra.

Na medida em que todas as obras da UC Digitalis se encontram protegidas pelo Código do Direito de Autor e Direitos Conexos e demais legislação aplicável, toda a cópia, parcial ou total, deste documento, nos casos em que é legalmente admitida, deverá conter ou fazer-se acompanhar por este aviso.




REVISTA DE HISTORIA DAS IDEIAS IO
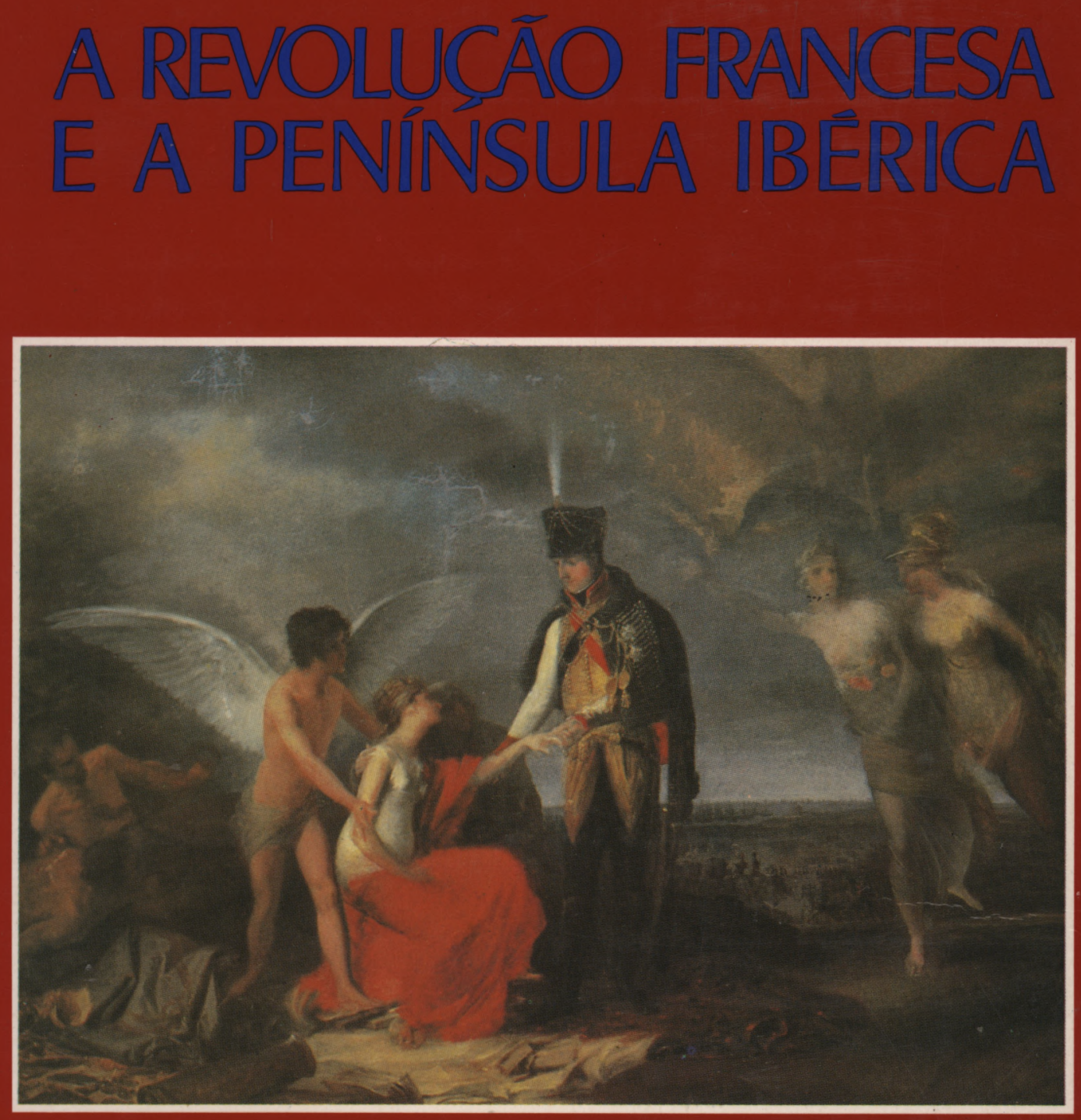

INSTITUTO DE HISTÖRIA E TEORIA DAS IDEIAS FACULDADE DE LETRAS 
BRAZ AUGUSTO AQUINO BRANCATO*

\section{A CARTA CONSTITUCIONAL PORTUGUESA DE 1826 NA EUROPA: UM EXAME A PARTIR DE DOCUMENTOS ESPANHÓIS}

O problema da sucessão portuguesa foi um dos temas que preocuparam não apenas ao próprio D. João VI, mas também toda a Nação lusitana, às demais Cortes europeias e, até mesmo aos brasileiros. Tal preocupação está bem presente antes mesmo da curta e última enfermidade do monarca português.

A Europa que desde a Revolução Francesa, não obstante uma série de vicissitudes, avançava, inexoravelmente, rumo a uma nova ordem política, tratava de deixar para trás o Antigo Regime que as ocorrências do 1789 francês haviam colocado em xeque e que a Santa Aliança tratava, desesperadamente, de salvar, defendendo o princípio da «legitimidade». Esta situação de busca de mudanças ameaçava o débil equilíbrio de forças da Europa, fazendo com que qualquer transformação política que adviesse pudesse converter-se numa complicada e importante questão internacional.

Portugal, devido aos seus tradicionais laços de amizade e de certa dependência em relação à Grã-Bretanha, se apresentava, na segunda década do século XIX, como peça de enorme importância no tabuleiro político das grandes potências europeias. Assim, atrair este Reino Peninsular para a órbita de influência de qualquer outra monarquia que não a britânica suporia, necessariamente, uma desestabilização no aludido equilíbrio, não somente por influências de ordem económica como também por aquelas de ordem política.

O rumo político que viesse a tomar Portugal poderia aproximá-lo ainda mais da Grã-Bretanha - caso seguisse o rumo liberal - ou, distanciá-lo no caso contrário e, em tal

* Pontifícia Universidade Católica do Rio Grande do Sul. Porto Alegre - RS - Brasil. 


\section{Revista de História das Ideias}

caso viabilizaria o alinhamento com outras potências concorrentes da Inglaterra e, muito especialmente, possibilitaria a criação de um bloco peninsular ibérico de carácter absolutista. E preciso ter presente que, desde 1823 a Espanha de Fernando. VII voltara a abolir a Constituição de 1812 que havia sido restaurada em 1820. Portugal também retornara a um governo não constitucional no mesmo ano porém, como é bem conhecido, entre a forma de governar de Fernando VII e a mantida por D. João VI existe uma grande e fundamental distância.

Desta maneira, o problema da sucessão lusitana passava a ser uma preocupação suficientemente forte a ponto de preocupar e colocar em estado de alerta as Cortes europeias em geral e, muito particularmente aos Gabinetes de Madrid e St. James.

Ao próprio rei de Portugal não escapava a percepção da transcendência que tinha o problema. $O$ Monarca não tinha junto a si nenhum de seus filhos varões; um, D. Pedro, tinha permanecido no Brasil onde acabou sendo aclamado e coroado Imperador, assumindo, assim, as rédeas do novo Estado independente, o outro, D. Miguel, após a tentativa de golpe absolutista de Abril de 1824 teve que sair de Portugal e, se encontrava em Viena.

A solução a que se pudesse chegar no momento de vir a ocorrer a sucessão ao trono lusitano, obviamente, poderia mudar o curso da história daquela conturbada década e, até mesmo, apagar a ilusão sempre acalentada por D. João VI de ver as Coroas de Portugal e Algarves, juntamente com a do Brasil, novamente reunidas numa mesma cabeça: a de seu filho mais velho D. Pedro.

No entanto, o facto de, há muito, a eventual sucessão portuguesa preocupar a tantas pessoas e governos não implicou em que ao produzir-se, efectivamente, a situação estivesse equacionada. Na realidade, quando em 10 de Março de 1826 expirava D. João VI, nada estava resolvido de facto. Pelo contrário esta data marca, isto sim, mais do que a morte do rei, o início de um dos problemas políticos mais graves da Nação portuguesa: a divisão entre aqueles que aceitam a $\mathrm{D}$. Pedro como legítimo sucessor de seu pai e aqueles que não reconhecendo tal legitimidade advogam que a Coroa de D. João VI deveria ser cingida por $\mathrm{D}$. Miguel.

$E$ bem verdade que tal discussão - que não é objecto deste trabalho - é algo que vai além de uma simples querela dinástica ou de uma discussão jurídica; ela é, na verdade, muito mais uma luta entre duas facções políticas com propostas antagónicas. De um lado estavam os liberais que viam em $\mathrm{D}$. Pedro IV a possibilidade de que, finalmente, o constitucionalismo 


\section{A Carta Constitucional Portuguesa}

fosse restaurado naquele Reino peninsular enquanto, por outro lado os absolutistas que viam em $\mathrm{D}$. Miguel o monarca que garantiria a reafirmação dos princípios mantenedores do Ancien Régime.

Assim, como ficou dito, o problema sucessório lusitano importava muito, não só para Portugal como também para o resto da Europa e Brasil e, como teremos oportunidade de verificar, tal questão ganhará, ainda, maior relevância após o conhecimento nas diversas Cortes europeias de que D. Pedro IV havia resolvido dar aos seus súbditos uma Carta Constitucional o que, naturalmente, reavivava nos liberais europeus e, especialmente, nos ibéricos a chama da esperança do retorno a uma ordem constitucional.

\section{O problema sucessório}

Com a morte de D. João VI a 10 de Março de 1826, herda a Coroa seu filho D. Pedro, facto aceite pelo Conselho de Regência presidido pela Infanta Isabel Maria ( $\left.{ }^{1}\right)$ que, imediatamente, tratou de comunicar a D. Pedro a infausta notícia bem como tratou, logo, de tomar as providências no sentido de o Reino passar a ser governado em nome de D. Pedro IV. Assim, no dia 20 do mesmo mês publicava a seguinte Portaria:

"....Que todas as Leis, Cartas Patentes, Sentenças, Provisões e quaisquer Diplomas ou Títulos que se costumão expedir em nome do Soberano, sejão 'passados n'esta fórma:=D. Pedro, por graça de Deos, Rei de Portugal e dos Algarves, d'aquem e d'além mar, em Africa Senhor da Guiné, e da Conquista, Navegação e Commercio da Ethiopia, Arabia, Persia e India, etc....» (2).

Com o intuito de deixar claramente demonstrado o seu entendimento de que $\mathrm{D}$. Pedro era o legítimo e único herdeiro

(1) D. Toão VI estando enfermo assinou, no dia 6 de Marco de 1826, um Real Decreto nomeando uma Regência provisória. presidida por sua filha a Infanta Isabel Maria e integrada, ainda, pelos "Conselheiros de Estado Cardeal Patriarca Eleito. Duaue de Cadaval, Marquez de Vallada. Conde dos Arcos, e o Conselheiro Ministro e Secretario de Estado em cada huma das seis respectivas Secretarias de Estado" para onvernar durante sua doenca ou "para o caso, em que Deos seja Servido Chamar-Me á Sua Santa Gloria, em quanto legitimo Herdeiro e Successor desta Corồa não der as Sıras providencias a este respeito....».

(2) Cf. Manifesto dos Direitos de Sua Magestade Fidelíssima a Senhora Dona Maria Segunda e Exposição da Questão Portuguesa, 2." edição, Coimbra, Imprensa da Universidade, 1841, pp. 6 e 7 (provas). 


\section{Revista de História das Ideias}

de D. João VI, o Conselho de Regência, no dia 16 de Abril daquele 1826 determinou que se dirigisse ao Rio de Janeiro uma representação com a finalidade de prestar homenagem ao novo rei em nome da Nação portuguesa. Tal missão partiu na nau «D. João VI», no dia 26 de Abril e era presidida pelo Duque de Lafões, irmão do Duque de Cadaval quem, como se viu, integrava o mencionado Conselho.

A notícia da morte do rei português foi conhecida no Brasil no dia 24 de Abril ( ${ }^{3}$ ), data em que aportou no Rio de Janeiro o bergantim de guerra lusitano "Providência» que saíra de Lisboa no mesmo dia da morte do Monarca.

D. Pedro I do Brasil ao receber a notícia da morte de seu pai e, portanto, de que por via de consequência passava a ser - além de Imperador do Brasil - rei de Portugal, teve que enfrentar-se com um sério problema: como conciliar a manutenção das duas Coroas?

A manutenção das duas Coroas, sob o ponto de vista legal, era perfeitamente aceitável já que a Constituição do Império do Brasil em nenhum de seus artigos o impedia $\left(^{4}\right)$. Porém se sob o ponto de vista estritamente legal não havia qualquer empecilho $\left(^{5}\right)$, na realidade, de facto, deter as duas Coroas apresentava-se como uma tarefa impossível de ser levada a cabo.

Efectivamente, a ferida produzida pela separação política entre os dois Estados ainda não tinha cicatrizado. Os brasileiros temiam que seu Imperador ao fazer-se cargo do trono lusitano colocasse em situação de perigo a própria independência do Império e, desta maneira, não admitiriam que $\mathrm{D}$. Pedro pudesse vir a assumir as duas Coroas e mais, que viesse a governá-los desde o Reino europeu. Por outro lado, é sobejamente conhecido que os portugueses ainda não tinham conseguido esquecer que seu novo rei tinha desempenhado um importantíssimo papel na perda da parte americana do «Império Lusitano» e, finalmente, não aceitariam ser governados desde o Brasil.

(3) O próprio Imperador D. Pedro I confirma tal data no quarto parágrafo da Fala do Trono que pronunciou no dia 6 de Maio de 1826, ná abertura da Assembléia Geral.

(4) Veja-se especialmente os artigos 1; 7 e 104.

(5) Muitos "miguelistas» utilizam como argumento para corroborar sua posição contrária aos possíveis direitos de D. Pedro, justamente o texto constitucional brasileiro de 1824, alegando, dentre outras coisas que D. Pedro ao aceitar a Coroa portuguesa estaria incurso no previsto no artigo 7, perdendo, desta maneira, a nacionalidade brasileira e, por isto não poderia assumir a chefia do Reino português. 


\section{A Carta Constitucional Portuguesa}

Diante de tais dificuldades, D. Pedro assumiu e manteve a Coroa portuguesa apenas por um curto espaço de tempo; o suficiente para poder dar ao seu novo Reino uma Constituição, editar algumas leis e adotar uma série de providências que julgou necessárias naquele contexto $\left(^{6}\right)$.

E de destacar também que $D$. Pedro tratou de garantir a tranquilidade do Estado português mantendo uma atitude conciliatória: assegurar os direitos que acreditava, firmemente, ser portador, os de suceder a seu pai no trono português e, a realidade dos factos. Ninguém - e muito menos D. Pedro deixava de ter conhecimento da oposição que sofria em Portugal e que aqueles que propugnavam pela adopção de uma postura absolutista, proclamavam o direito de D. Miguel em suceder a D. João VI, alegando, dentre outras coisas, que D. Pedro ao independizar o Brasil tinha decaído dos seus direitos de herdeiro do trono luso. Desta forma, D. Pedro tratou de solucionar tal problema, abdicando da Coroa portuguesa em favor de sua filha mais velha, Dona Maria da Glória, ao mesmo tempo em que determinava que ela deveria casar com seu tio D. Miguel que, desta maneira, viria a ser «rei consorte».

Convém destacar que esta solução adoptada por D. Pedro não foi, como poderia pensar-se, uma fórmula encontrada a partir de uma busca surgida concomitantemente com o problema relativo à sucessão de D. João VI. Na verdade, não cabe qualquer dúvida de que esta solução já havia sido pensada por D. Pedro muito tempo antes de que surgisse o impasse de 1826. Efectivamente, já em carta do dia 19 de Junho de 1822, o então Príncipe Regente escrevia desde o Rio de Janeiro a seu pai o seguinte:

«Peço a Vossa Magestade que deixe vir o Mano Miguel para cá seja como for. Elle he aqui muito estimado, e os Brazileiros o querem ao pé de mim para me ajudar a servir no Bazil, $e$ a seu tempo cazar com minha filha Maria [da Glória]. Espero q. Vossa Magestade lhe dê licença, e lhe não queira cortar a sua fortuna, quando Vossa Magestade como Pay deve por obrigação Christam, contribuir com todas as suas forças para a felicidade de seus filhos». (7) [O grifo é nosso].

Como se pode verificar, parece que D. Pedro já então vislumbrava problemas que poderiam vir a ocorrer quando,

(6) São exemplos: o Decreto do dia 26 de Abril de 1826 mantendo a Regência que havia sido nomeada por D. João VI; o Decreto do dia 27 do mesmo mês concedendo amnistia e as várias Cartas Régias do dia 30 nomeando Pares do Reino e ordenando a eleição de Deputados.

(7) Cf. Angelo Pereira, Os filhos d'el Rei D. João VI, Lisboa, Empresa Nacional de Publicidade, 1946, pp. 291-92. 
cedo ou tarde, a questão sucessória portuguesa pudesse apresentar-se e, é claro que, a estas alturas, a possibilidade de 0 Brasil vir a se tornar um Estado independente não era tão remota.

A atitude de $\mathrm{D}$. Pedro frente ao problema que se lhe apresentava, naturalmente, não afectava apenas aos dois Estados directamente ligados à questão. Interessava muito de perto também às demais nações europeias já que, dependendo, como se viu, das soluções que fossem adoptadas, Portugal poderia passar a ser um forte elemento desestabilizador dentro da Europa.

Também é importante que se tenha em conta que às potências europeias - principalmente as da Santa Aliança - se apresentava um problema que tinha que ser examinado com muito cuidado para poderem resolver sem correr o risco de derrubar o princípio da legitimidade, tantas vezes defendido por elas. $\mathrm{Na}$ verdade não reconhecer $\mathrm{D}$. Pedro como legítimo. sucessor de D. João VI implicaria em considerar nulos vários documentos em que o rei como tal o considerava $\left(^{8}\right)$.

Desta maneira não restava a tais potências outra solução que não a de reconhecer formalmente a D. Pedro IV como legítimo rei de Portugal e, como tal, legalmente capacitado para determinar todas as mudanças políticas que the parecessem cabíveis na estrutura do Estado português, uma vez que ele havia herdado um trono onde o rei detinha em si todos os poderes.

Assim, quando as Cortes europeias vieram a tomar conhecimento das medidas adoptadas por D. Pedro IV no Rio de Janeiro, com relação a Portugal, já o haviam reconhecido como sucessor de seu pai. Qualquer outra atitude poderia colocar em dúvida o próprio princípio da «legitimidade» tão arduamente defendido pela Santa Aliança. Por outro lado, considerar que D. Pedro havia perdido seus direitos à sucessão por assumir a Coroa Imperial brasileira e, ter assim cometido crime de lesa majestades e de lesa pátria, obrigaria também a que, na mesma situação, fosse considerado o Infante D. Miguel que havia tentado um golpe de Estado contra seu pai, no conhecido episódio da "Abrilada».

De todas as maneiras, a situação portuguesa, como declarou o Ministro britânico George Canning ao Representante brasileiro, Barão de Itabayana, no dia 23 de Março de 1826, «éra

(8) Tal seria o caso da Carta Patente de 13 de Maio de 1825 e da Carta da Lei de 15 de Novembro de 1825, ambos diplomas relativos ao reconhecimento do Brasil como Estado independente de Portugal. 


\section{A Carta Constitucional Portuguesa}

negocio de geral interesse para as Potencias da Europa» $\left(^{(}\right)$, com o que se pode compreender o grande interesse britânico na solução do problema português de maneira a não vir a perder sua posição junto àquele Reino. Também a situação brasileira preocupava como se pode verificar claramente nos termos da entrevista que o Barão de Itabayana teve com o Ministro de S. M. Britânica e que relata no citado ofício do dia 23 de Março onde se pode ler:

«....que lhe parecia [Canning] que a opinião publica no Brasil éra contraria á reunião das duas Coroas na Pessoa de Sua Magestade Imperial; e que o Governo de Sua Magestade Britannica, sem pretender de modo algum influir na resolução de Sua Magestade Imperial, julgava que, na qualidade de antigo amigo da Augusta Familia de Bragança lhe éra permittido manifestar francamente a Sua Opinião ao Mesmo Augusto Senhor sobre um negocio de tão transcendente importancia....

Leo-me então Mr. Canning hum Despacho mui bem redigido, em que, depois de haver feito as mais judiciosas reflexoens sobre a impossibilidade que ha de conservar Sua Magestade Imperial a Corôa do Brasil, residindo em Portugal, e sobre a difficuldade que teria de manter a de Portugal, continuando á residir no Brasil, propõe o unico arbitrio que lhe parece acertado, e exequivel, e he $o$ seguinte:

$10^{\circ}$ O de renunciar Sua Magestade Imperial a Corôa de Portugal na Pessoa de Sua Augusta Filha a Senhora Princeza Dona Maria da Gloria, Mandando-a inmediatamente para Lisboa.

2. O de ajustar o Casamento d'Ella com o Serenissimo Infante Dom Miguel, para quando Ella chegar ao estado de nubilidade.

3.० $O$ de conservar a Sierenissima Senhora Infanta [Isabel Maria] na Presidencia da Regencia, até que a Rainha possa assumir». [Os grifos são nossos].

Cabe destacar que fica extremamente clara a preocupação do Gabinete de St. James em tentar tranquilizar Portugal buscando diminuir a tensão interna através do expediente de acenar aos «miguelistas» com a possibilidade de, com o decorrer do tempo, vir D. Miguel, por via de casamento, ocupar o trono lusitano. Fica nítida também a intenção britânica de fazer com çue o retorno de $\mathrm{D}$. Miguel para Portugal se retardasse o máximo possível, mantendo a Presidência do Governo nas mãos

(9) Ofício do Barão de Itabayana enviado de Londres ao Visconde de Santo Amaro notificando-lhe de uma entrevista que havia mantido com George Canning. AHI - 217/3/1 - Legação Imperial na Inglaterra; Ofícios Reservados - 1824/1831. 
de Dona Isabel Maria até que a «Rainha possa assumir» o trono $\left({ }^{10}\right)$.

Era, ainda, pretensão da Grã-Bretanha fazer com que, enquanto não se pudesse consumar o casamento, D. Miguel continuasse «as suas viagens pela Europa...., adquirindo luzes para ajudar a sua esposa na laboriosa tarefa do governo do Reino....» (11). Não resta a menor dúvida de que $\mathrm{D}$. Miguel não era propriamente a pessoa a quem o governo britânico queria ver em Portugal naqueles conturbados e decisivos dias. Era muito possível que seu retorno a Portugal pudesse se configurar no elemento que faltava para que os absolutistas capitaneados por Carlota Joaquina, tomassem as rédeas do Reino, alinhando-o com a política de Fernando VII e das demais potências de tendências absolutistas.

No entanto, o «Despacho» de Canning, pelo menos o transmitido pelo Barão de Itabayana a Santo Amaro, só foi recebido no Rio de Janeiro no dia 6 de Junho, conforme consta no próprio documento. Quer isto dizer, bastante tempo depois de que D. Pedro tivesse decidido sobre o assunto e, inclusive consultado pessoas de sua confiança $\left({ }^{12}\right)$. Já havia, como é sabido, abdicado o trono lusitano em favor de sua filha mais velha, providenciado para que se preparasse os esponsais dela com o Infante D. Miguel e, ainda, outorgado aos portugueses uma Carta Constitucional.

Estas medidas adoptadas por D. Pedro porém, não conseguiram atingir seus objectivos de tranquilizar Portugal. A abdicação, o contrato de casamento da Rainha com o Infante e, até mesmo a nomeação de $\mathrm{D}$. Miguel como «Lugar Tenente» de seu irmão em Portugal não foram suficientemente fortes para contrapor-se à outorga da Cara Constitucional. Esta outorga conseguiu reacender as disputas entre liberais e absolutistas.

Repercussões da Carta Constitucional Portuguesa no Exterior

Além das contendas que se travaram dentro mesmo de Portugal, é importane que se tenha presente o facto de que idade.

(10) Dona Maria da Glória contava, então, com sete anos de

(11) Idem, nota 9.

(12) Sobre estas consultas veja-se, principalmente, a feita ao Visconde de Barbacena e os conselhos que este dá pois coincidem com as medidas adoptadas, logo, pelo Imperador. Cf. António Augusto de Aguiar, Vida do Marquez de Barbacena, Rio de Janeiro, Imprensa Nacional, 1896, pp. 121-23. 


\section{A Carta Constitucional Portuguesa}

o conhecimento da outorga da Carta aos portugueses desencadeou uma série de reacções em outros Estados. Entre eles se destaca a vizinha Espanha onde Fernando VII desde a intervenção dos «Cem mil filhos de São Luís» voltara a reinar de maneira absolutista.

Efectivamente, o Portugal constitucional representava para o soberano espanhol um grande perigo já que tal experiência bem poderia "contaminar» a Espanha com o temido «germe» constitucional, facto que os exilados liberais espanhóis viam com muita clareza, como no caso de Antonio Alacalá Galiano que escreveu $\left({ }^{13}\right)$ :

«Así estaban las cosas cuando de súbito, mediado 1826, llegó a Inglaterra la noticia de que muerto D. Juan VI, rey de Portugal, su hijo y heredero don Pedro, residente en el Brasil.... renunciando su cetro europeo, lo había puesto en manos de su hija, menor de edad, acompañando la dádiva con la de una Constitución a su pueblo. No era este suceso de poca monta, porque una ley de las llamadas por antonomasia Constitución, y de hecho creaba un poder popular, mal podía existir en una parte de la Península Ibérica sin que a la otra algo se comunicase».

Por tais razões, Fernando VII, além de impor um rígido controle na correspondência que entrava na Espanha, estabeleceu também uma forte vigilância nas fronteiras por onde pudessem chegar pessoas vindas do país vizinho $\left({ }^{14}\right)$, tomou ainda, outras providências tendentes a coibir um possível contágio constitucional.

Ao mesmo tempo em que Madrid adoptou tais medidas, tratou de desencadear uma campanha junto às demais Cortes europeias para que não reconhecessem o novo regime implantado em Portugal.

O Bourbon espanhol logo que teve conhecimento das determinações de D. Pedro IV relativas a Portugal, nomeou D. Joaquín de Anduaga para exercer uma «misión extraordinaria en la Corte de Lisboa» dando-lhes as seguintes instruções $\left({ }^{15}\right)$.

(13) Recuerdos de un Anciano, in: Obras escogidas de Antonio Alcalá, Madrid, Ed. Atlas (Biblioteca de Autores Españoles, v. 83), 1955, p. 219.

(14) Cf. Joaquín del Moral Ruiz, «Realistas, miguelistas y liberales. Contribución al estudio de la intervención española en Portugal (1826-1828)", in: José María Jover Zamora, et al. Estudios del Siglo XIX en España: doce estudios, Barcelona, Ed. Planeta, 1974, pp. 241-43.

(15) Cf. cópia destas instruções dadas em Madrid no mês de Julho de 1826 (não consta o dia no documento mas foram dadas nos primeiros dias do mês). AMAE. Legajo 2608. Portugal Política Ext., 1826-27. 
«V.I. està enterado de los decretos por los cuales el Rey de Portugal ha dado desde el Brasil una Constitución à sus Estados de Europa.... Tamb.én se halla V.I. bien penetrado de los pelıgros que amenaza a la España y aun à la Europa en el caso en que lo referido decreto de Constitución se lleve a efecto y por tanto creo ocioso detenerme en hacer referencias sobre ellos. Así pues el obgeto de la misión de V.I. es el de emplear todos los medios posibles para lograr que la actual Regencia de Portugal suspenda la ejecución del decreto hasta que pueda conocer cual es el modo de pensar de las Potencias de Europa sobre medida tan preñada de consecuencias temibles....» [0 grifo é nosso].

$\mathbf{E}$, segue mais adiante, nas mesmas instruções, indicando que Anduaga deveria tentar deter a publicação da Carta Constitucional, tratando de demonstrar, ainda, à Regência os graves e imprevisíveis riscos que tal atitude poderia desencadear. Assim, indicava que:

«Para obtener dho. obgeto V.I. deverà emplear todos los resortes de la diplomacia no solo con los individuos de la Regencia y Ministros, sino trabajando incesantemente en que los representantes de las Potencias en aquella Corte le ayuden en tan importante empresa, persuadiendo a todos en conversaciones particulares de las consecuencias que infaliblemente tendrían en la peninsula el establecimiento de la Constitución por el estado en que se halla la opinion publica española la cual seria dificil contener; y enfin convenciendoles de que seria encender una guerra en la Peninsula y aun en Europa con inminente peligro de los tronos....».

Por sua vez, D. Joaquín de Anduaga, ainda em Madrid, no dia 9 de Julho daquele ano, escrevia ao Duque do Infantado $\left({ }^{16}\right)$, fazendo uma análise da situação que se poderia criar ccm a efectiva implantação, em Portugal, da Carta. Ao mesmo tempo tece várias considerações e observações sobre os possíveis caminhos que, a seu juízo, a Espanha poderia tomar no caso de que a Carta Constitucional, outorgada por D. Pedro IV, viesse a ser jurada em Portugal.

Resumidamente, os possíveis caminhos vislumbrados por Anduaga são os seguintes: $1^{\circ}$ ) reconhecimento do novo regime; $2^{\circ}$ ) declarar guerra a Portugal e, $3^{\circ}$ ) não reconhecer o governo constitucional e «sin declaración de guerra cortar nuestras relaciones diplomáticas con aquella Corte».

Após apontar estes três caminhos tratava de mostrar as dificuldades e inconvenientes que cada um deles apresentava,

(16) AMAE. Legajo 2607. Portugal Política Ext. 1820-26. 
sugerindo, finalmente, que dada a urgência com que as decisões teriam que ser tomadas, fossem:

\begin{abstract}
«....expedidas instrucciones al representante del Rey en Lisboa, previniendole que si la Constitución se adopta diga que no tiene ordenes para eso.... absteniendose de todo paso que pueda significar reconocimiento......
\end{abstract}

Propunha, ainda, que no caso de que a Espanha se decidisse reconhecer o novo regime, tratasse, antes, de negociar e assinar um Tratado através do qual Portugal se comprometesse expressamente a não permitir a estada e, muito menos a permanência em seu território de refugiados espanhóis. Sugeria também que se comprometesse, o governo português, a impedir qualquer «intriga para turbar el reposo de la España», destacando ainda que tal «Convención debe ser el sine qua non del reconocimiento, y sin ella es preferible la guerra con todos sus peligros».

A preocupação era tão grande com um vizinho constitucional que o mesmo Anduaga chega ao ponto de propor ao governo espanhol que caso não fosse possível impedir a definitiva implantação do regime constitucional em Portugal, a Espanha tratasse de negociar com as demais potências estrangeiras e, especialmente, com a França um «tratado de garantia (como el q. tiene Portugal con la Inglaterra) por el cual se le asegura la integridad de su territorio y el actual sistema de Gobierno...».

Desta maneira, a Espanha tratava de se preparar para enfrentar um perigo que sentia eminente. Baralhava as mais variadas hipóteses até mesmo a de uma guerra contra Portugal, que sabidamente envolveria outras Nações.

Fernando VII buscou saber qual a opinião que tinha seu Conselho de Estado a esse respeito. Para tanto nomeou uma Comissão que deveria examinar as citadas observações de Anduaga $\left({ }^{17}\right)$. Esta se pronunciou sobre o tema enviando ao Duque do Infantado dois ofícios: um no dia 13 de Julho e outro no dia seguinte $\left({ }^{18}\right)$. No primeiro manifestava a opinião de que seria conveniente que o Governo enviasse «una Nota Circular, ó un Memorandum á las Grandes Potencias, Francia, Austria, Prusia y Rusia, haciendo ademas una manifestación como de familia al Rei Cristianisimo, el mas interesado en oponerse á los enmascarados proyectos de la Inglaterra». Remetia, em

(17) Esta Comissão estava integrada pelo Bispo de Leão, Frei Cirilo de Alameda e o Conde de Venadito.

(18) AMAE. Legajo 2607. Portugal-Política Ext. 1820-26. 


\section{Revista de História das Ideias}

anexo, uma minuta da nota que julgava que deveria ser enviada às Representações Diplomáticas espanholas junto às Cortes indicadas $\left({ }^{19}\right)$.

Já no segundo ofício, o do dia 14, a Comissão insistia na necessidade de que fosse buscado o apoio exterior, muito especialmente $o$ francês, para que pudesse ser preservado o regime espanhol contra qualquer sublevação que eventualmente surgisse com o exemplo e, até mesmo, conivência do governo português. Assim, a Comissão sugere:

«....parecenos oportunisimo que se abriera una negociación con el Gabinete de la Tullerias, para obtener del Rei Cristianisimo como Gefe de la familia, que declarara mantendría el Gobierno Español contra los ataques de cualquier otro gobierno, sin que ninguno se atreviera ni á hostilizarle, ni a intentar variaciones en la forma que lo hizo la Inglaterra con respecto al Portugal, cuando despues del Congreso de Verona resolvió el difunto Rey Luis 18 la entrada de sus tropas en nuestro territorio....».

O mesmo tema foi, ainda, tratado na reunião do Conselho de Estado do dia 18 do mesmo mês $\left({ }^{20}\right)$ quando o Secretário da Guerra chamou a atenção dos Conselheiros sobre o perigo que representavam as medidas adoptadas por D. Pedro IV que, segundo ele, poderiam ameaçar a própria estabilidade da monarquia espanhola e, por tal razão proporia ao Soberano que tomasse todas as medidas que estivessem ao seu alcance «para pervenir los males que pudiesen sobrevenir de semejantes desagradables sucesos».

Como se pode verificar, Fernando VII não estava disposto a esperar que os acontecimentos se desenvolvessem sem que ele e os seus tratassem de tentar, de alguma maneira, intervir neste desenvolvimento.

Declarar guerra contra Portugal estava claro desde o início, não era uma solução sequer viável: a Espanha não dispunha nem mesmo dos meios económicos para sustentá-la e, qualquer indivíduo de mediana inteligência sabia que a Grã-Bretanha não contemplaria impassível qualquer invasão a Portugal. Diante disto ao governo espanhol não restava senão a possibilidade de tentar junto a outros Reinos europeus que se opusessem ao regime constitucional lusitano, ao mesmo

(19) Minuta da mencionada Nota se encontra-se no Arquivo e Legajo citados na nota anterior.

(20) Cf. Acta da Reunião de 18 de Julho de 1826. ANHM - Sección de Estado. Libro 30. Actas del Consejo de Estado. 1826. 


\section{A Carta Constitucional Portuguesa}

tempo em que poderia procurar minar a resistência interna do regime português buscando desestabilizá-lo, utilizando para tal os refugiados portugueses anticonstitucionais que se encontravam em território espanhol.

Múltiplos são os exemplos em que se poderia mostrar tal atitude mas, parece suficiente que vejamos o que foi tratado na sessão do Conselho de Ministros da Espanha do dia 3 de Novembro em cuja acta consta:

«El Sr. Secretario de Estado y del Despacho de Gracia y Justicia principió la sesion de este dia manifestando que habia dado orden S.M. p." q. ${ }^{\circ}$ hiciese presente al Consejo que las tropas Portuguesas refugiadas en España harian probablemente de un momento á otro una incursion en su pais, con el fin de hostilizar á los revolucionarios; y que siendo verosimil que se quejen los Extranjeros de que las hemos dejado marchar, era su soberana voluntad se tratase de la contestacion q. ${ }^{\bullet}$ podria darseles. El Sr. Ministro de la Gyerra confirmó cuanto antecede añadiendo que el Rey N.S. queria se protegise indirectamente este movimiento pero sin comprometerse el Gobierno de modo alguno; y despues de haber convenido todos los s.res Secretarios del Despacho en a. ${ }^{\circ}$ este era el unico $v$ verdadero medio de derrocar la Constitucion de Portugal y en aue p.r ningun título ni pretexto debemos en las circunstancias actuales atacar de frente à aquel Gobierno sino abarentar p.r el contrario los mayores deseos de aue no se turben las relaciones de buena amistad y vecindad, dió una idea del plan que tenian concertado los Gefes Portugueses n." llevar á cabo su empresa $v$ de las medidas a ${ }^{e}$ han tomado los Capitanes Generales de Castilla la Vieja y de Galicia p." proporcionarles Armas....»(21).

Efectivamente, os esforços da Espanha em inviabilizar o governo constitucional português foram os mais amplos possíveis $\left.{ }^{22}\right)$. E, justamente, nesta linha de acção que vamos encontrar um enorme esforço diplomático espanhol que coincide com uma série de mútuas consultas entre as principais potências europeias na busca de uma solução para o problema que se apresentava.

E por demais conhecido que a notícia da outorga da Carta Constitucional Portuguesa havia caído como uma verdadeira

(21) Cópia da Acta do "Consejo de Ministros del 3 de Nov. de



(22) Sobre o assunto convém examinar: Ignacio Pedro Ciordia Liberal, «España en la segunda crísis Constitucional Portuguesa (desde la muerte de D. Juan VI al reconocimiento de D. Miguel I)", Cuadernos de Historia, Madrid, Instituto Jerónimo Zurita, Consejo Superior de Investigaciones Científicas, 1973, 4; 163/236, bem como Joaquín del Moral Ruiz, ob. cit. 


\section{Revista de História das Ideias}

bomba em boa parte da Europa e, de certa maneira, os Governos, cheios de perplexidade, não sabiam exactamente que atitude tomar. Muitas coisas estavam em jogo: desde as próprias bases sobre as quais se assentava a política do «concerto europeu» até a eventualidade de que ante uma atitude agressiva contra Portugal, a Grã-Bretanha enviasse tropas para garantir o novo governo lusitano.

A situação europeia ainda apresentava uma série de problemas outros e, qualquer acréscimo poderia vir a ser um enorme perigo. Não se pode esquecer que a França, então, mantinha, ainda, tropas suas na Espanha desde a entrada dos «Cem Mil Filhos de São Luís» em 1823. A Rússia, por sua vez, tinha um grande interesse em que a Grã-Bretanha lhe deixasse livre a via para tratar dos assuntos do Oriente e dos Balcãs, assuntos estes que tinham sido objecto de um acordo firmado por Wellington no dia 4 de Abril de 1826 em São Petersburgo (23)

A Austria, por sua parte, apesar da nítida aversão ao constitucionalismo, além de ter em conta que a Carta vestida do manto da legitimidade, não podia deixar de considerar que a mesma garantia a abdicação de $\mathrm{D}$. Pedro em favor de Dona Maria da Glória (artigos 5 e 86), neta do Imperador austríaco. Por sua vez a Prússia, embora também se opusesse ao novo sistema de governo, se mantinha na expectativa do que seria decidido pelas demais potências.

De todas as maneiras é interessante destacar que se havia dúvidas quanto a que atitudes deveriam ser adoptadas, já não as havia quanto ao mal estar geral causado. Assim, no dia 23 de Junho daquele ano, desde Paris, o Duque de Villahermosa escrevia ao Duque do Infantado um ofício classificado como «Muy Reservado», onde dizia:

«....Las resoluciones del Emperador del Brasil han causado un disgusto grande y general á este Ministro de relaciones exteriores y á todos los Representantes de la S.ta Alianza, incluso al de Austria, que tal vez es quien mas se ha pronunciado en este sentido....» (24).

Já, segundo o Enviado de Sua Majestade Católica na Rússia, em correspondência ao Duque do Infantado $\left({ }^{25}\right)$, o governo

(23) Sobre este tema, entre outros, veja-se Ana María Schop Soler, Un Siglo de Relaciones Diplomáticas y Comerciales entre España y Rusia - 1733-1833, Madrid, Ministerio de Asuntos Exteriores, Dirección General de Relaciones Culturales, 1984, pp. 371 e ss.

(24) AMAE, Legajo 2608. Portugal - Política Ext., 1826-27.

(25) Cópia do ofício n..$^{\circ}$ 260, Moscovo, 14 de Agosto de 1826, AHNM - Sección de Estado - Legajo 6134, caja 1-Rusia, Corresp. de Embajada, 1826. 


\section{A Carta Constitucional Portuguesa}

russo havia deixado bem clara a sua posição de não adoptar nenhuma atitude sem antes conhecer as reacções que as mudanças impostas por D. Pedro IV viessem a produzir em Lisboa. Acrescentava ainda que, nenhuma postura seria adoptada sem receber «alguna comunicación del Gabinete Inglés». Sobre o mesmo assunto o Enviado espanhol, no dia 14 de Agosto, encaminhava também um ofício cifrado ao Secretário de Estado da Espanha esclarecendo:

«....este Emperador se incomodó muy de veras y se penetró de todas las correspondencias de la novedad del Portugal diciendo.... que aflijiria justamente al Rey de España. y aumentará das dificultades en todos los Gobiernos....» (26).

No entanto, não reconhecer as mudanças políticas introduzidas em Portugal era já impossível. Não poderiam as potências europeias tardar em fazê-lo. Já haviam reconhecido a D. Pedro IV como legítimo sucessor de D. João VI e, por muito que lhes desagradasse não tinham cutra opção. Neste sentido se expressou com muita clareza Nicolau I da Rússia em conversa com o Enviado espanhol junto àquela Corte, D. Juan Paez de la Cadena, que transmite esta conversa a seu Governo através de um ofício enviado de Moscovo no dia 26 de Setembro $\left({ }^{27}\right)$, relatando nos seguintes termos a audiência que tivera:

a...S.M.I., en la larga audiencia que me concedió tubo á bien manifestarme especialmente con relación a los asuntos de Portugal y de nuestras Americas....

S.M.I. empezó por asegurarme cuam vivamente había sentido desde la primera noticia las innovaciones que se anunciaban en Port? gal, $y$ cuando preveía podían ser funestas á la tranquilidad aue tanto deseaba en nuestra España y aun acaso de toda Furopa: pero que sin embargo por el arte y maña con que habian sido preparadas, $v$ modo inesperado con aue eran introducidas, alycionando por desgracia á un Monarca, y haciendolas así derivar de un origen tan resnetahle $v$ legitimo, hnhin creido aue era preciso ser consiguiente con los Princinios, y resnectar hasta en sus errores el de la Legitimidnd. aue tantns esfuerzos había costado el restablecer en Europa, $v$ tan del interés de los Mnnarcas era el conservar ileso. Oue baio éste concepto habia desde lyego creido aue no era va tiempo, ni menos politico ni exento de fatales consecuencias el intentar una onosición directa á las indicadas innovaciones». [0 grifo é nosso].

6134, raia 1

(26) Cópia do ofício n.o 216. AHNM, Sección de Estado, Legajo

(27) AMAE, Legajo 2609. Portugal - Política Ext., 1826-28. 


\section{Revista de História das Ideias}

De qualquer forma, o governo espanhol não esmorecia na busca de conseguir, no plano internacional, o apoio necessário para suas pretensões com relação a erradicação do "perigo liberal» da Península Ibérica. Desta maneira, no dia 12 de Outubro do mesmo ano de 1826, enviava a seus representantes diplomáticos na Áustria, França, Prússia e Rússia uma Nota que deveriam entregar aos respectivos Governos junto aos quais estavam acreditados, salientando o enorme perigo que a nova experiência constitucional lusitana poderia representar, especialmente para a Espanha $\left({ }^{28}\right)$.

$\mathrm{Na}$ tentativa de impedir a sobrevivência da Carta portuguesa, o governo espanhol, como acto extremo, não teve qualquer dúvida em invocar o precedente francês de 1823 que conseguiu pôr um ponto final na experiência constitucional espanhola de 1820. Neste sentido o Embaixador espanhol em Paris, Duque de Villahermosa, por ordem de seu Governo, no dia 21 de Outubro, encaminhou ao Ministro de Assuntos Estrangeiros da França, Barão de Damas, uma solicitação de auxílio para impedir a manutenção de um Governo constitucional em Portugal. A tal pedido o Ministro francês respondeu nos seguintes termos:

«A la première nouvelle des evènements qui ont suivi de près la mort de Roi Jean VI, le Roi de France a prévu l'inquiétude que causerait à Sa Majesté Catholique le changement qui se préparait dans la forme du gouvernement de Portugal son premier soin a été de se concerter avec ses alliés les moyens de prévenir les changes dangereuses que pouvait faire naître l'exaltations des esprits qui trouvant respectivement en Portugal et en Espagne un aliment à leurs passions. mettaient en péril la paix qui règne entre les deux gouvernements. Le plus sûr de ces movens était de faire sentir de part d'autre la nécessité de prudence et d'empecher tout acte hostile. C'est ce dont la France s'est occupée avec zèle: son opinion comme ses efforts, en ce sens, on été partagés par ses alliés» (29).

$\mathrm{E}$, segue o Ministro francês dizendo do grande interesse que tem o rei da França em manter a paz e a tranquilidade

(28) Minuta enviada junto ao ofício do mesmo dia, por D. Manuel González Salmón. Secretario de Estado ao Ministro espanhol em São Petersburgo. AHNM - Serción de Estado, Legajo 6134, caja 2, Rusia Corresp. de Embaiada, 1826.

Além de ser enviada às Legações mencionadas, também foi encaminhada uma cópia "al ministro en Londres p." su gobierno», conforme consta do despacho existente na cópia da citada Nota que se encontra no AMAE, Legaio 2608. Portugal - Política Ext., 1826-27.

(29) AMAE, Legajo 2608. Portugal - Política Ext., 1826-27. 
na Península Ibérica, ao mesmo tempo em que chama a atenção para a peculiaridade do caso português e, sua marcada diferença com precedente invocado por Fernando VII, afirmando que

\begin{abstract}
«....elle [Sua Majestade Cristianíssima, Carlos X] doit rappeler que lorsque, en 1823, Louis XVIII, de gloriéuse mémoire, se détermina à faire entrer son armée en Espagne, il adopta cette grande mesure, non parcequ'il y existait alors une forme de gouvernement Constitutionnel, mais parce que le changement de gouvernement avait été imposé à Sa Majesté Catholique par une révolte par la force et que dés lors, il devait être considéré comme illégitime et attentatoire aux droits de tous les Souverains.

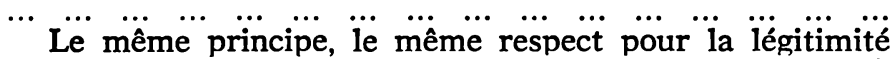
qui avaient porté Louis XVIII à prendre les armes et à secourir la Monarchie Espagnole, ont déterminé le Roi à ne point se prononcer contre la forme de gouvernement qu'il a plu à l'Empereur Don Pèdre de donner au Portugal, et qui, émanée d'un autorité légitime, a dû prendre le même caractére. Cette rèole de conduite a été adoptée par tous les souverains de l'Europe.....
\end{abstract}

Como se pode verificar, também o governo francês se negava a adoptar qualquer forma de represália contra as determinações do rei de Portugal, deixando bem claro que nem ele nem os demais poderiam tomar qualquer atitude, pelo menos de maneira oficial, contra as mudanças políticas introduzidas em Portugal.

Pela documentacão examinada se pode verificar que a atitude de $\mathrm{D}$. Pedro IV, efectivamente, obrigou mesmo àqueles Monarcas de tendência marcadamente absolutista, a tratarem de não se opor à implantação de uma nova Constituição na Europa. Todos reconheciam o risco que corriam caso Portugal se tornasse um exemplo a mais, contudo nada podiam fazer sob pena de negarem os princípios que vinham, de há muito, tratando de defender. A Carta portuguesa chegara com o selo da legitimidade!

\footnotetext{
ABREVIATURAS:

AGMJ - Archivo General del Ministerio de Justicia - Madrid.

AHI - Arquivo Histórico do Itamaraty - Ministério de Relações Exteriores - Rio de Janeiro.

AHNM- Archivo Histórico Nacional - Madrid.

AMAE - Archivo del Ministerio de Asuntos Exteriores - Madrid.
} 